\title{
Multiple lesions by vampire bat bites in a patient in Niterói, Brazil - Case report
}

\author{
Fred Bernardes Filho', \\ Bernard Kawa Kac ${ }^{4}$ \\ David Rubem Azulay ${ }^{1,4,7}$
}

\author{
Gustavo Martins ${ }^{2}$ \\ José Augusto da Costa Nery ${ }^{1,5}$
}

\author{
Gustavo Sabaini Luchi ${ }^{3}$ \\ Luna Azulay-Abulafia ${ }^{1,6}$
}

\begin{abstract}
Over the last few centuries, the expansion of urbanization brought bats closer to urbanized areas, increasing the risk of accidents by bat bites. The morphology of bat bites can be varied, usually having an elliptical shape, about $0.5 \mathrm{~cm}$ along its greatest length, and the characteristic corkscrew bite pattern. The authors present the case of a patient who was repeatedly bitten by vampire bats for two months. A polymerase chain reaction was performed in the cutaneous nerves at the base of the hair follicles which showed negativity towards the rabies virus. The authors highlight the public health importance of this case, and discuss the morphological characteristics of these hematophagous bat bites.
\end{abstract}

Keywords: Bites and stings; Chiroptera; Rabies

\section{INTRODUCTION}

There are several species of bats in Brazil, but only three of them are hematophagous. The Desmodus rotundus species, known as "vampire bat", is widely distributed in most of the Brazilian territory and is found in larger numbers than the other hematophagous bat species (Figure 1). ${ }^{1}$ The presence of hematophagous bats in the city of Rio de Janeiro is known since mid-19th century, when the species Desmodus rotundus was identified in a description of an attack to equines that belonged to Charles Darwin entourage, at Praça $\mathrm{XV}$, downtown of the then federal capital, in 1852. ${ }^{2}$

Today, most acknowledged attacks by chiroptera, in the capitol of the state of Rio de Janeiro, have occurred in the outskirts of Maciço da Tijuca. ${ }^{2}$ In Niterói, a city in the metropolitan area of Rio de Janeiro, in the period of 2006 to 2010, complaints related to bats represented $10.8 \%$ out of a total of 1,552 occurrences registered at Animal Population Control Section of the city's Zoonoses Control Center (Centro de Controle de Zoonoses - CCZ). ${ }^{3}$
Bats of the Desmodus rotundus species have large and sharp incisive teeth, which are used to make precise superficial cuts on their prey, from which they lick the blood., ${ }^{4,5}$ The bite of these hematophagous mammals usually has an elliptical shape about $0.5 \mathrm{~cm}$ long at its greatest length. ${ }^{4}$

We present the case of a patient who, in spite of taking the prescribed serum vaccination for human rabies due to contact with bats, did not present seroconversion and continued exposing himself to chiroptera biting, virtually daily, for a period of two months.

\section{CASE REPORT}

Male patient, 42 years old, residing in Bairro Sapê, city of Niterói, was admitted with complaints of multiple bat bites. He reported his condition had started approximately two months before; for around three consecutive days, upon waking up, he noticed the presence of a great amount of blood on the place where he was sleeping, like the mattress and couch. Initially, he associated his symptoms to alcohol and

Received on 21.07.2013.

Approved by the Advisory Board and accepted for publication on 01.08.2013.

* Work performed at Instituto de Dermatologia Professor Rubem David Azulay - Santa Casa da Misericórdia do Rio de Janeiro (IDPRDA-SCMRJ) - Rio de Janeiro (RJ), Brazil.

Conflict of interest: None

Financial funding: None

Instituto de Dermatologia Professor Rubem David Azulay - Santa Casa da Misericórdia do Rio de Janeiro (IDPRDA- SCMRJ) - Rio de Janeiro (RJ), Brazil

Private Clinic - Ituiutaba (MG), Brazil.

Instituto Philippe Pinel (IPP) - Rio de Janeiro (RJ), Brazil

Pontifícia Universidade Católica do Rio de Janeiro (PUC-RJ) - Rio de Janeiro (RJ), Brazil.

Fundação Oswaldo Cruz (LaHan-Fiocruz) - Rio de Janeiro (RJ), Brasil.

Universidade do Estado do Rio de Janeiro (UERJ) - Rio de Janeiro (RJ), Brazil.

Fundação Técnico-Educacional Souza Marques and Universidade Federal do Rio de Janeiro (UFRJ) - Rio de Janeiro (RJ), Brazil. 
drug abuse; however, on the fourth day, he observed several bats on his body. He went to the Basic Health Unit (Unidade Básica de Saúde - UBS), where he underwent prophylaxis post-exposition to a potentially rabies-transmitting animal, with a total of five doses of vaccine and antirabies serum therapy. Although he followed the appropriate prophylaxis, he reported that everyday he slept in his house, he was bit again. He returned to UBS with the same complaint other times, however it was overlooked due to the previous associated chemical dependency.

At the physical exam, he presented weakened physical condition and precarious personal hygiene; cardiopulmonary and neurological evaluations were both normal. At the dermatological exam, multiple erythematous lesions were observed, with ulcerated and excoriated areas, some with the corkscrew morphology, in the cervical region, left ear, forearms, hands, thighs, legs, ankles and feet; he presented subungual ecchymoses on halluces, with signs of trauma in the digital pulp of these toes (Figures 2 to 6). Exams were performed, whose results detected: elevation of liver enzymes - AST: 121, ALT: 61; Gamma GT: 189; Hc: 3.2 million/mm3; Hb: 10; Ht: 30; blood glucose, electrolytes and renal function were normal; serology for hepatitis, syphilis and HIV negative; unchanged chest radiograph, absence of AARB and Histoplasma capsulatum in sputum and to Ziehl-Neelsen and India ink staining respectively.
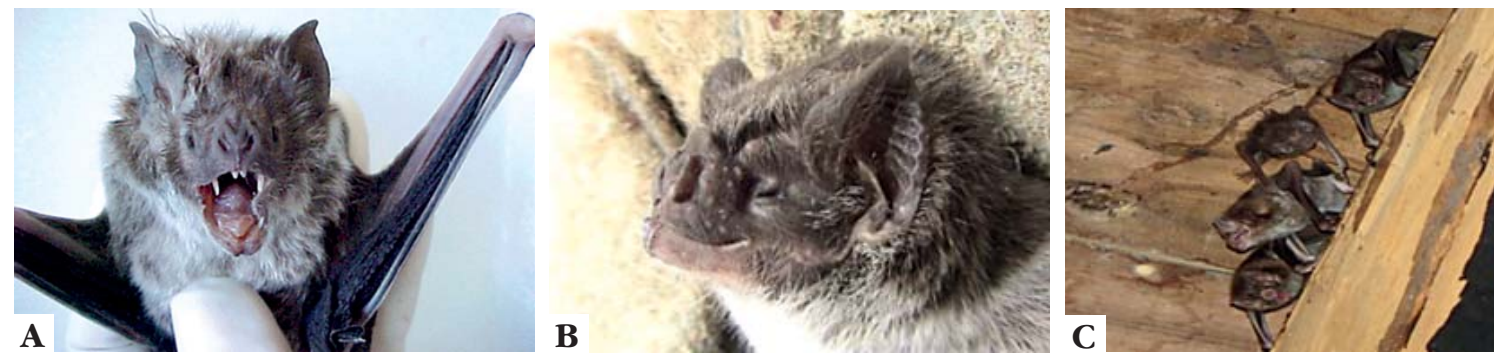

Figure 1: Desmodus rotundus - hematophagous bat. (a) Observe the incisive teeth that are big and sharp; (b) Detail of the nose appendix, characteristic of the species; (c): Bats in a basement. Courtesy of PhD Leda Kimura
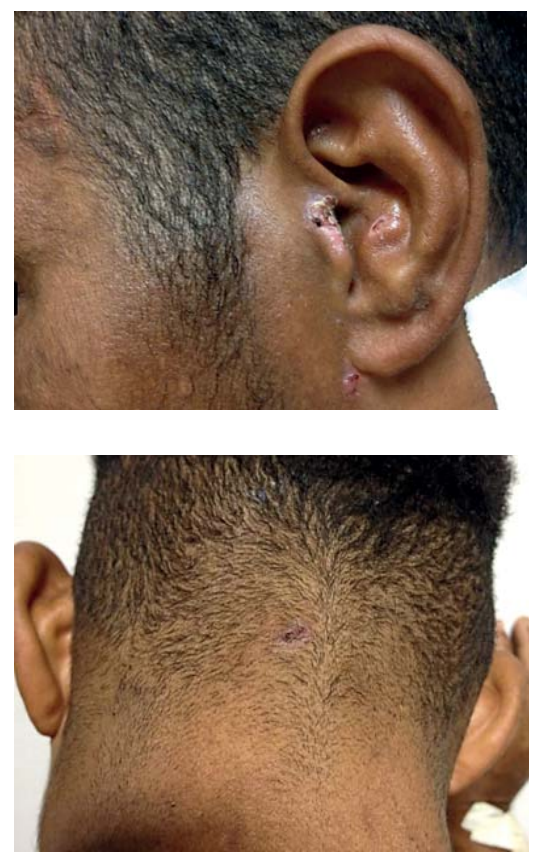

FIGURE 2:

Exulcerated and ulcerated lesions on the tragus region and on the cavum to the left

Figure 3:

Erythematous lesion with ulcerated center

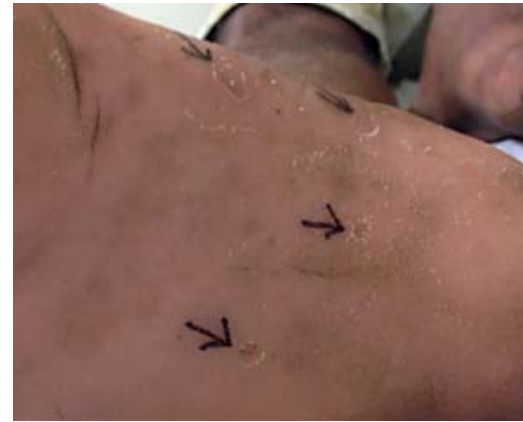

Figure 4: Presence of multiple "corkscrew" lesions on right foot plantar region

Skin biopsy of the cervical region, at the hair implantation line, covering an area with around 20 strands, and the polymerase chain reaction (PCR) for the rabies virus were performed, with negative results. Human antirabies antibodies titration did not present seroconversion.

In light of this, a medical visit was paid to the patient's house, located in the periurban area; the absence of doors, windows, part of the ceiling and basic sanitation were noticed. On the outside there was a mattress with several blood stains. The case was 

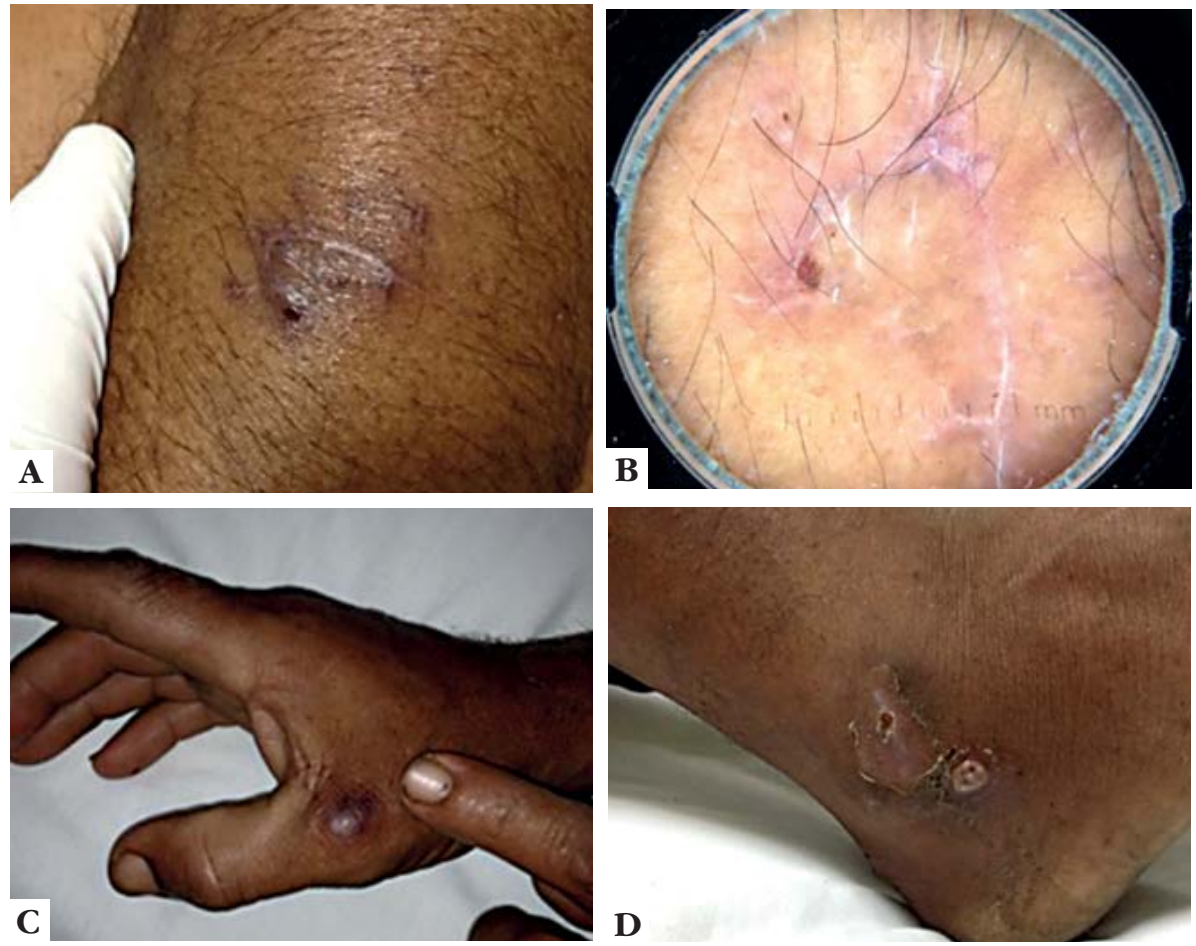

Figure 5:

A - Purplish erythematous plaque of irregular borders, with presence of excoriations and ulcerated area on right forearm; B Dermoscopy of the

forearm lesion showing ulcerated area and linear and angular excoriations compatible with scratches and bat bites; C -

Brownish erythematous nodule on the metacarpophalangeal region of the first right finger; $\mathbf{D}$ Lesions with exulcerated center and peripheral scaly collar on maleolar region of right ankle
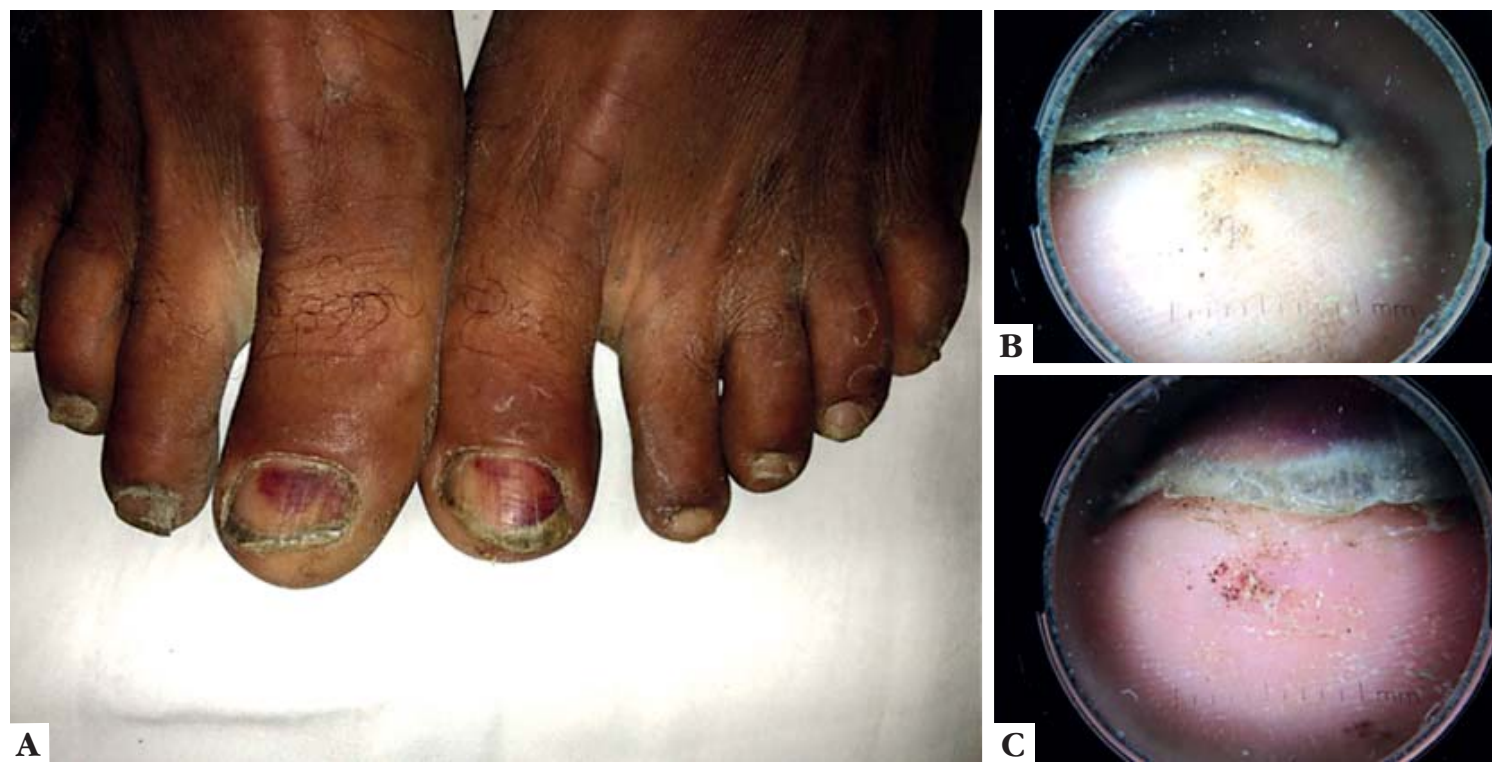

Figure 6: A - Subungual ecchymoses on both halluces. Detail of extremities showing multiple red dots on hallux digital pulp - right B and left C, compatible with several perforations caused by bats bites 
reported to CCZ- Niterói and the patient was admitted to a rehabilitation clinic, by his own decision.

\section{DISCUSSION}

In the period from 1990 to 2010, 581 cases of human rabies were recorded, of which, from 2004 onwards, the main vector was the bat. ${ }^{6}$ The presence of the rabies virus was also demonstrated in nonhematophagous chiroptera populations, in the city of Rio de Janeiro. ${ }^{7}$

The in vivo laboratory confirmation of human rabies cases can be done by the direct immunofluorescence method (DIF) or by polymerase chain reaction (PCR), on cutaneous nerves of hair follicles, obtained by skin biopsy of the cervical area. ${ }^{8,9}$ The importance of knowledge about this valuable diagnostic procedure is emphasized to dermatologists.

The typical morphology of a vampire bat bite is a "corkscrew" pattern; with opening and closing movements of the mouth, the bats bite and remove a fragment of skin: epidermis and part of the dermis. ${ }^{4}$ Superficial blood vessels are lesioned and the bleeding provided by these vessels accumulates on the lesion, working as a feeding source for the chiropteran. Besides being superficial, the feeding bite is apparently painless, for the vampire bat has an anesthetic substance, in addition to a factor Xa inhibitor denomi- nated draculin and a plasminogen: DSPA (Desmodus Salivary Plasminogen Activator) ${ }^{4,10}$ The fingers and dorsum of feet, calcaneal region, hands, elbows, scalp, ears, forehead, nose tip and lips are the places most often bitten by bats. ${ }^{1,4,5,6}$ The patient presented lesions with the characteristic pattern of bat bites; it is probable that the subungual ecchymoses on both halluxes are present due to multiple perforations on the tips of the toes, caused by several bites.

The anemia arising from injury and chemical dependence is a factor that favors an immunosuppression clinical picture and, as a result, the non seroconversion to rabies. It is the authors' opinion that the patient probably did not have his complaint seriously considered at UBS because it was interpreted as a psychotic picture with somatization and delirium. Accidents with bats, like the above reported case, represent a grave risk to public health, and require attention, prevention and control measures by the competent authorities.

\section{ACKNOWLEDGEMENTS}

To PhD Leda Maria Silva Kimura, Coordinator of Research at PESAGRO RIO.

To the reviewers of this article, for suggestions and for the term "corkscrew" to describe the morphology of vampire bat bites. $]$

\section{REFERENCES}

1. Martins, Felipe de Mello. Filogeografia intraespecífica do morcego hematófago Desmodus rotundus (Chiroptera, Phyllostomidade) [tese]. São Paulo (SP): Universidade de São Paulo; 2008. 153 p.

2. Esberard C, Cifali A, Santos A, Thebas F. Action of vampire bats in Rio de Janeiro city. Rev Bras Med Vet. 2001;23:219-20.

3. Moutinho FFB, Rocha MRD, Borges FVB, Pereira AG, Serra CMB. Community complaints to the Animal Population Control Section of the Zoonosis Control Center of Niterói, RJ, Brazil, from 2006-2010. Rev Bras Ci Vet. 2013;20:26-31.

4. Brasil. Ministério da Saúde. Fundação Nacional de Saúde Morcegos em áreas urbanas e rurais: Manual de manejo e controle. Brasília: Fundação Nacional de Saúde; 1998. 117 p.

5. Kimura LMS. Epidemiologia molecular de vírus da raiva em mamíferos domésticos e silvestres do Brasil [tese]. Rio de Janeiro (RJ): Fundação Oswaldo Cruz; 2006. 79 p.

6. Brasil. Ministério da Saúde. Secretaria de Vigilância em Saúde. Departamento de Vigilância Epidemiológica. Normas técnicas de profilaxia da raiva humana. Brasília: Ministério da Saúde; 2011. 60 p. (Série A. Normas e Manuais Técnicos).

7. Cabral CC, Morais AC, Dias AV, Araújo MG, Moreira WC, Mattos GL. Circulation of the rabies virus in non-hematophagous bats in the City of Rio de Janeiro, Brazil, during 2001-2010. Rev Soc Bras Med Trop. 2012;45:180-3.

8. Macedo Cl, Carnieli Jr P, Brandão PE, Travassos da Rosa ES, Oliveira Rde N, Castilho JG, et al. Diagnosis of human rabies cases by polymerase chain reaction of neck-skin samples. Braz J Infect Dis. 2006;10:341-5.

9. CDC.gov [página na internet]. Centers for Disease Control and Prevention. Rabies ante mortem testing. [acesso 15 Jul 2013]. Disponivel em: http://www.cdc.gov/rabies/specific_groups/doctors/ante_mortem.html.

10. Ciprandi A, Horn F, Termignoni C. Saliva of hematophagous animals: source of new anticoagulants. Rev Bras Hematol Hemoter. 2003;25:250-62.

How to cite this article: Bernardes Filho F, Martins G, Luchi GF, Kac BK, Nery JAC, Azulay DR. Multiple bites by vampire bats in a patient: a case report in Niterói, Brazil. An Bras Dermatol. 2014;89(2):340-3. 